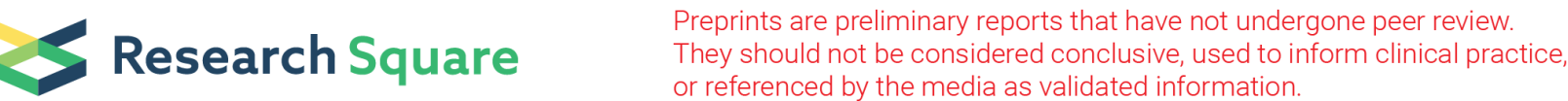

\section{Parents' Perceived Mental Distress When Their Infant is Admitted to a Neonatal Intensive Care Unit (NICU) a Quantitative Cross-Sectional Study}

Inger Hilde Hagen ( $\boldsymbol{D}$ inger.h.hagen@ntnu.no )

Norges Teknisk-Naturvitenskapelige Universitet Fakultet for Medisin og Helsevitenskap

Marit Føllsvik Svindseth

Norges Teknisk-Naturvitenskapelige Universitet Fakultet for Medisin og Helsevitenskap

Frøydis Perny Vasset

Norges Teknisk-Naturvitenskapelige Universitet Fakultet for Medisin og Helsevitenskap

Research article

Keywords: neonatal care, parents, mental health, intensive care, infant

Posted Date: August 7th, 2020

DOI: https://doi.org/10.21203/rs.3.rs-42463/v1

License: (c) (i) This work is licensed under a Creative Commons Attribution 4.0 International License.

Read Full License 


\section{Abstract}

Background. It is normal for parents to experience a range of emotions and changes in behaviour while their newborn infant is in the NICU. The stress experienced by these parents during their infant's hospital stay is found to affect the parent-infant relationship and their ability to bond reciprocally. Several studies have pointed out that support from family and friends can be useful for parents' mental distress in this situation. Some differences are found between mothers' and fathers' experiences of the support. The aim of the current study is to examine parents' perceived mental distress when their infant is admitted to a neonatal intensive care unit (NICU) and factors important for their support. The relationship between parents perceived mental distress and satisfaction with NICU care are spare researched.

Methods. A multicentre prospective cohort study. A total of 568 parental participants from six different NICUs geographically spread throughout Norway. Hospital Anxiety and Depression Scale (HADS) and Impact of Events Scale-Revised (IES-6) were used to collect data. All the responses were rated and analysed using parametric analysis methods, descriptive statistics, logistic regression, factor analyses and linear regression analyses.

Results. A total of 275 mothers reported receiving support from family and friends compared with 232 fathers. Younger parents had a higher OR of reporting anxiety compared with that of older parents. Parents with a primary or high school education level showed a higher OR of satisfaction than did parents with a college or university education level.

Conclusion. There are differences in mothers' and fathers' responses to their experiences of various distress symptoms related to their children being in the NICU, as well as their received support from family and friends. There are also outcome differences between the age and education level of the parents and their experience of stress in the NICU. Mothers are more distressed and have more anxiety and depression than do fathers have.

Trail registration: This project was first presented to the Regional Committees for Medical and Health Research Ethics which reported that the project was outside its mandate $(2015 / 386)$. The project is approved from the Norwegian Data Protection Officials.

\section{Background}

One potentially stressful life event is the birth of a child. It is not surprising that the birth

of a critical ill or preterm infant who is cared for in a neonatal intensive care unit (NICU) can be particularly stressful for the parents (1-4). In the NICU, infants receive around-the-clock care from a team of experts. Parenting in the NICU is different and challenging compared with parenting a healthy infant at home. Some studies have shown that the parents of NICU infants experience higher rates of psychological distress compared with parents of full-term, healthy infants (1-7). It is normal for parents to experience a range of emotions and changes in behaviour while their newborn infant is in the NICU. 
Some parents may find it difficult to deal with these feelings. Early physical separation from the infant within $24 \mathrm{~h}$ of birth is related to an increase in parents' NICU-related stress (8). Many of the parents face months of acute stress disorder (ASD), post-traumatic stress disorder (PTSD), anxiety and depression (9, 10). The stress experienced by these parents during their infant's hospital stay is found to affect the parent-infant relationship and their ability to bond reciprocally (11). In addition to differences in the stress levels between the parents of preterm and full-term infants, studies have also examined differences between the fathers and mothers of preterm infants $(3,12-15)$.

The aim of this study was to examine parents' perceived stress, anxiety and depression in relation to parents' characteristics and level of satisfaction with the NICU.

Depression and postpartum depression (PPD) are characterized by decreased motivation, lowered mood or apathy, loss of interest in activities, loss of joy, and loss of energy, and they may be related to more serious symptoms such as fatigue and disturbed sleep (16). Anxiety often co-occurs with depression and is characterized by feelings of uneasiness and fear towards a non-existing threat with several somatic sensations. There may be an association between parents' mental distress, stress and worry for their sick newborn or premature child and symptoms of anxiety and depression (17-20). PPD and PTSD are found to be a risk for both fathers and mothers when they have an infant hospitalized in the $\operatorname{NICU}(18,21,22)$. Separation from the infant and the interruption of the relationship between parents and newborns contribute to aggravating the already weakened family emotional state, which is commonly manifested by acute anxiety (23); Correia, Rocha \& Dittz, 2019). A high stress score is also associated with a higher level of depressive symptoms $(24,25)$.

High parental scoring on PTSD symptoms has been associated with not only several health problems in both parents and children but also an increase in the length of hospital admissions to NICUs. Traumatic events can have a negative influence on the child's development both physically and mentally (10). It has also been found that the fathers of preterm infants have more postnatal depressive symptoms than the fathers of full-term infants. Fathers' depressive symptoms also negatively impact infants' early cognitive function (26). Research (Cheng et al., 2016; Naryayanan \& Nærde, 2016) has also found that mothers are likely to have more depression symptoms when they have children in the NICU than are fathers.

Most studies report that mothers experience more distress than fathers $(3,12-15)$. Despite these observations, some studies have not found the expected high levels of parental stress $(7,27,28)$. Research indicates that young mothers ( $<25$ years of age) and their partners are more likely to experience stress and new depression than are older parents. Both new and recurrent stress and depression are more common among parents with low education levels compared with those with higher education levels (Liu et al., 2016., Enke et al., 2017).

In summary, research shows that symptoms of depression and anxiety can negatively impact the developing relationship between parents and children in NICUs. It is therefore important for all employees to be aware of these reactions/symptoms from an early stage to limit or prevent the potentially negative health effects for all concerned. 
Involving parents in the care of the infant is reported to reduce stress and increase confidence in parents and to increase their satisfaction with the overall care received in the NICU (29-32). Several factors reflect the pressing need for family-centred care (FCC) and the support of the families of infants in NICUs; the identification of parental needs, familiar stress and a lack of parenting confidence; and gaps in support for families, as identified by parents (30). FCC can be summarized as a clinical practice approach that includes some core principles such as the coordination of care attained by means of effective communication, the provision of information and education to the family, respect and understanding, and the physical and emotional support and the involvement of parents in decision-making and in care (33). Support from family and friends is also found to be an important factor for parents of infants in NICUs. Parents who have such support are also found to be more satisfied with NICU services (34).

The current research questions are as follows:

- What differences can be found between parents' characteristics and perceived mental distress in NICUs?

- What self-reported comparisons are there between the mental health of mothers and fathers and their support from family and friends when their infants are admitted to NICUs?

\section{Method}

\section{Aim}

The aim of the current study is to examine parents' perceived mental distress when their infant is admitted to a neonatal intensive care unit (NICU) and factors important for their support.

\section{Design}

A multicentre prospective cohort study was conducted between September 2015 and October 2016. The study consists of a non-experimental design in which a defined group of people is followed over time to study outcomes in the cohort (35). The population and data collection method of this study are the same as in previous research $(34,36)$, but in this study we investigated parents perceived mental distress and therefore used questionnaires not reported in the previous studies. The study methods were compliant with the STrengthening the Reporting of OBservational studies in Epidemiology (STROBE) checklist of cross-sectional studies (Additional file1).

\section{Study population and setting}

The participants were Norwegian or English-speaking parents of infants admitted to one of six NICUs whose admissions lasted for more than two days to have a time basis for expressing their views. The infants' gestation ages ranged from 24 to 42 weeks.

Parents whose children died while in the unit were excluded from this study. Due to reports from the nurses collecting the data, the parents who did not answer the survey were lost mostly due to 
administrative reasons and exclusion criteria, and we concluded that our sample was most likely representative.

\section{The sampling strategy}

The recruitment process followed a strategic selection according to the inclusion criteria. All six participating NICUs were organized quite similarly and shared the same philosophy of treatment and care. The participating NICUs varied in size from 6 to 21 beds (mean of 12.5) and treated between 253 and 500 patients each year. Two NICUs are located in university hospitals, and the rest have regional or local catchment areas. Three units treat children of gestation age $(G A) \leq 23$, while the rest provided care for children from GA 26-30.

\section{Data collection methods}

The first author introduced the study to the unit nurses. Three research assistants located at each hospital were responsible for questionnaire distribution and collection. During the data collection, the first author maintained regular contact with the research assistants via telephone, email and/or visits. The research assistants in the participating NICUs identified parents who were eligible study participants. As the discharge time approached, the research assistant contacted the infants' next of kin to secure their informed consent to take part in this study. The research assistant left a copy of the self-reported questionnaire with participating parents a few days before their discharge from the unit. Parents with multiple births received only one questionnaire. To ensure confidentiality, the parents dropped their completed survey form in a secured box at the unit. The response rate for the six hospitals participating in the study varied from 33 to $66 \%$, and the mean participation rate was $45 \%$. The level of missing data was low (mean 1.1\%) for the final survey, which suggests that the questionnaire is acceptable to respondents.

\section{Measures}

\section{Sociodemographics}

The mothers and fathers answered questions on demographic variables, such as age, level of education, native language, main income, civil status, and driving distance from home to hospital. The parents were also asked about their infant's gestation age, number of children, and support from family and friends.

In this study, we used the Hospital Anxiety and Depression Scale (HADS), developed by Zigmond and Snaith in 1983. The scale is commonly used to determine the levels of anxiety and depression that patients experience. The HADS is a fourteen-item scale, seven of which relate to anxiety and seven of which relate to depression $(37,38)$.

We also used the Impact of Events Scale-Revised (IES-6), which is a shorter version of the IES-22 originally developed by Horowitz, Wilner and Alvarez (1979). The IES-6 is an abbreviated version developed by Thoresen et al. (2010) and has 6 items, i.e., two items for intrusion, two for avoidance and two for hyperarousal. The respondents were asked about the distress caused by their symptoms rather 
than their frequency. The Likert scale response format used a 5-point scale. Correlation with the IES-6 across samples was high (pooled correlation $=0.95$ ). To measure parents' total satisfaction with neonatal intensive care units, we used the Neonatal Satisfaction Survey (NSS-8) developed and validated by Inger Hilde Hagen et. al $(2018)(34,36)$.

\section{Ethics}

The study was conducted according to the Declaration of Helsinki. This project was first presented to the Regional Committees for Medical and Health Research Ethics, nor2015/386/REK nord, which reported that permission to conduct the project was not necessary. The project was approved by the Norwegian Data Protection Authority. After having read an information letter concerning the study, all the respondents were asked for oral and written consent to participate. We emphasized that participation was voluntary and that parents could withdraw from the study at any time.

\section{Analysis}

Descriptive statistics were conducted. The mothers' and fathers' characteristic differences were analysed with a Pearson chi-square test, ( $p$-value set to $\leq 0.05$ ). T-tests were performed to examine the comparisons between the level of the mothers' and fathers' perceived stress, anxiety and depression symptoms. All the significance tests were two-tailed. Logistic regression was performed to assess the associations between the sociodemographic variables, support and the likelihood that the parents would report anxiety and depression. Cohen's $d$ was used to analyse to report the statistical strengths of differences. A d value of $<0.20$ is considered weak, that between 0.20 and 0.50 is considered moderate, and a $\mathrm{d}$ value of $>0.50$ is considered strong.

\section{Results}

This article focuses on the parents of newborns in intensive care units, their mental distress related to the situation and what supports them through the crisis. The study included returned questionnaire from 568 parents, of whom 312 (54\%) were mothers and 256 (45\%) were fathers. The response rate for the six participating hospitals varied from $33-66 \%$, and the mean was $45 \%$. The level of missing data in the completed forms was low (mean $1.1 \%$ ). Between several factors, support from family and friends was the most important factor for parents' perceived mental health.

Table 1 shows the descriptive statistics of the parents. The mean age of the mothers in the sample was 30 years (SD 5.50) and that for the fathers was 33 years (SD 6.94). There was a significant difference in education level between mothers and fathers $(p=0.013)$, with 184 mothers $(59 \%)$ reporting a higher level of education ( $\geq 4$ years) compared with 116 fathers (46\%). A total of $275(88 \%)$ mothers reported receiving support from family and friends compared with 232 fathers (91\%), and 131 (42\%) mothers and $110(43 \%)$ fathers reported receiving practical help with their other children. The travel time from home to the hospital was less than one hour for 156 (50\%) mothers and 137 (54\%) fathers. There was also a significant difference in reporting being alone as a caregiver between mothers and fathers $(p=<0.001)$, 
with 124 mothers (40\%) reporting being alone with the infant in the NICU versus 25 fathers (10\%). Most of the parents ( $N=537,96 \%)$ characterized their infant's health as good, while $22(4 \%)$ characterized their child's health as bad. Nearly all the parents $(\mathrm{N}=432,76 \%)$ reported being satisfied with the level of NICU care $(\mathrm{N}=237(76 \%)$ mothers and $\mathrm{N}=195(76 \%)$ fathers $)$. 
Table 1

Descriptive and comparative characteristics of mothers and fathers $(\mathrm{N}=568)$

\begin{tabular}{|c|c|c|c|c|}
\hline \multirow[t]{2}{*}{ Variables Mean (SD) } & $\begin{array}{l}\text { Mothers }(\mathrm{N}= \\
312)\end{array}$ & $\begin{array}{l}\text { Fathers }(\mathrm{N}= \\
256)\end{array}$ & $\begin{array}{l}\text { T-test p- } \\
\text { value }\end{array}$ & \multirow{2}{*}{$\begin{array}{l}\text { Total }(\mathrm{N}= \\
568) \\
\mathrm{N}\end{array}$} \\
\hline & $N(\%)$ & $N(\%)$ & & \\
\hline \multirow[t]{2}{*}{ Age } & $30.09(5.50)$ & $33.10(6.94)$ & $>0.001$ & 567 \\
\hline & & & $\begin{array}{l}X^{2} \text {-test } p- \\
\text { value }\end{array}$ & \\
\hline Level of education & & & 0.013 & \\
\hline Higher education $>4$ years & $76(24.4)$ & $50(19.7)$ & & 126 \\
\hline Higher education $<4$ years & $108(34.6)$ & $66(26.0)$ & & 174 \\
\hline College & $113(36.2)$ & $126(49.6)$ & & 239 \\
\hline Primary/high school & $15(4.8)$ & $12(4.7)$ & & 27 \\
\hline Total & $312(100)$ & $254(100)$ & & 566 \\
\hline $\begin{array}{l}\text { Receiving Support from } \\
\text { family/friends }\end{array}$ & & & 0.414 & \\
\hline Yes & $275(88)$ & $232(91)$ & & 507 \\
\hline No & $37(12)$ & $24(19)$ & & 61 \\
\hline Total & 312 & 256 & & 568 \\
\hline Practical help with other children & & & 0.513 & \\
\hline Yes & $131(42)$ & $110(43)$ & & 241 \\
\hline No & $11(4.0)$ & $7(3.0)$ & & 18 \\
\hline Not in need of & $169(54)$ & $139(54)$ & & 308 \\
\hline Total & 311 & 256 & & 567 \\
\hline Travel time & & & 0.404 & \\
\hline Less than one hour & $156(50)$ & $137(54)$ & & 293 \\
\hline More than one hour & $156(50)$ & $119(46)$ & & 275 \\
\hline Total & 312 & 256 & & 568 \\
\hline Alone as caregiver & & & $<0.001$ & \\
\hline No & $188(60)$ & $231(90)$ & & 419 \\
\hline Yes & $124(40)$ & $25(10)$ & & 149 \\
\hline
\end{tabular}




\begin{tabular}{|lllll|}
\hline Variables Mean (SD) & $\begin{array}{l}\text { Mothers } \mathbf{N}= \\
\mathbf{3 1 2}) \\
\mathbf{N}(\%)\end{array}$ & $\begin{array}{l}\text { Fathers }(\mathbf{N}= \\
\mathbf{2 5 6}) \\
\mathbf{N}(\%)\end{array}$ & $\begin{array}{l}\text { T-test } \mathbf{p}- \\
\text { value }\end{array}$ & $\begin{array}{l}\text { Total }(\mathbf{N}= \\
\mathbf{5 6 8})\end{array}$ \\
\hline Total & 312 & 256 & $\mathbf{N}$ \\
\hline Infant health & & & 0.514 & 568 \\
\hline Good & $294(95)$ & $243(97)$ & & 537 \\
\hline Bad & $14(5)$ & $8(3)$ & 24 \\
\hline Total & 308 & 251 & 559 \\
\hline Satisfaction with NICU care & & & 0.953 & \\
\hline High satisfaction & $237(76)$ & $195(76)$ & & 432 \\
\hline Low satisfaction & $75(24)$ & $61(24)$ & & 136 \\
\hline Total & 312 & 256 & & 568 \\
\hline
\end{tabular}

Of the 352 infants in the study (Table 2), 245 (70\%) were born premature (24-37 weeks), and there were 29 pairs of twins. Most of the parents $(N=347,61 \%)$ reported that their infants were hospitalized from 2 days to two weeks.

Table 2

Infant characteristics

\begin{tabular}{|ll|}
\hline Infants variables & $\mathbf{N}(\%)$ \\
\hline GA & \\
\hline $24-37$ weeks & $245(70)$ \\
\hline$\geq 37$ weeks & $107(30)$ \\
\hline Total & 352 \\
\hline Number of infants & \\
\hline Multiple birth & $29(1.0)$ \\
\hline Length of stay & \\
\hline 2 days -2 weeks & $347(61)$ \\
\hline 2 weeks & $221(39)$ \\
\hline Total & 568 \\
\hline
\end{tabular}

In Table 3, we report the parents' perceived anxiety. The logistic model included fourteen independent variables (GA, number of infants, length of stay, infant health, alone as the dependent variable, support 
from family/friends, help from families/friends, travel time, parent age, language, education level, income, civil status, and satisfaction with NICU care). According to Table 3, the model explained between $11 \%$ (Cox and Snell R square) and 17\% (Nagelkerke R squared) of the variance in anxiety status.

Table 3

Logistic regression predicting the likelihood of parents' perceived anxiety

\begin{tabular}{|lcl|}
\hline Sociodemographic variables and anxiety & OR $(95 \% \mathrm{CL})$ & $P$-value \\
\hline Support from family and friends & $1.58(1.13-2.21)$ & 0.007 \\
\hline Parents' age & $1.05(1.00-1.10)$ & 0.046 \\
\hline Parents' education level & $0.64(0.46-0.88)$ & 0.002 \\
\hline Infant health & $0.60(0.44-0.82)$ & 0.002 \\
\hline Cox and Snell R square $11 \%$, Nagelkerke R squared $17 \%, \mathrm{X}^{2}(14, \mathrm{~N}=568)=48.715, \mathrm{p}<0.01$. \\
\hline
\end{tabular}

The most important area was support from family and friends. The model indicated that the parents who reported receiving support from family and friends had an OR of not feeling anxious that was 1.58 times that of parents with no such support. Also, the parents who perceived their infants' health as good had an OR of not feeling anxious that was 0.60 times that of parents who perceived their infant's health as bad (controlling for all other factors in the model). Another important area was that of parents' age. Younger parents had an OR of reporting anxiety that was 1.05 times higher than that of older parents. The third most important area was parents' education level. Parents with a primary or high school eduction level had an OR of being satisfied that was 0.64 times that of parents with a college or university education level.

The logistic model in Table 4 shows the parents' perceived depression. This model included the same independent variables as those shown in Table 1. This model explained between 09\% (Cox and Snell R square) and 24\% (Nagelkerke R squared) of the variance in depression status. The parents' perceived support from family and friends, their satisfaction with NICU care and their infant's perceived health made unique and statistically significant contributions to the model. The most important area was satisfaction with NICU care. The parents who were not satisfied with NICU care had an OR of being depressive that was 3.36 times higher than that of parents who reported being satisfied. The parents who perceived their infants' health as good had an OR of not feeling depressed that was 0.57 times that of the parents who perceived their infant's health as poor (controlling for all other factors in the model). 
Table 4

Logistic regression predicting the likelihood of parents' perceived depression

\begin{tabular}{|lcc|}
\hline Sociodemographic variables and depression & OR $(95 \% \mathrm{CL})$ & $P$-value \\
\hline Satisfaction with NICU care & $3.36(1.38-8.15)$ & 0.007 \\
\hline Support from family and friends & $1.95(1.24-3.09)$ & 0.004 \\
\hline Infant health & $0.57(0.35-0.93)$ & 0.026 \\
\hline Cox and Snell R square 0.9\%, Nagelkerke R squared $24 \%, \mathrm{X}^{2}(14, \mathrm{~N}=568)=41.372, \mathrm{p}<0.01$. \\
\hline
\end{tabular}

Table 5 shows the parents' perceived stress. This model included the same independent variables as those shown in Tables 3 and 4. This model explained between 14\% (Cox and Snell R square) and 25\% (Nagelkerke R squared) of the variance in stress status. The parents' age made a unique and statistically significant contribution to the model. Younger parents had an OR of reporting stress that was 1.16 times higher than that of older parents, controlling for all other factors in the model.

Table 5

Logistic regression predicting the likelihood of parents' perceived stress

\begin{tabular}{|lcc|}
\hline Sociodemographic variables and stress & OR $(95 \% \mathrm{CL})$ & $P$-value \\
\hline Parents' age & $1.16(1.01-1.34)$ & 0.033 \\
\hline Cox and Snell R Square $14 \%$, Nagelkerke R square $25 \%, \mathrm{X}^{2}(14, \mathrm{~N}=568)=17.970, \mathrm{p}<0.01$ \\
\hline
\end{tabular}

In Table 6, we show the differences in mothers' and fathers' perceived stress, anxiety and depression symptoms. Significant differences between the mothers' and fathers' perceived stress were found in the IES-6. The mothers of infants admitted to the NICU had higher levels of total stress than did the fathers $(p=<0.001)$. The mothers also had more intrusive feelings $(p=<0.001)$ and avoidance $(p=<0.001)$ than did the fathers. The amount of variance explained by each model was moderate to small, and the highest value was that for avoidance (0.488). The mothers with an infant in the NICU had significantly higher total HADS $(p=0.004)$, anxiety $(p=0.002)$ and depression $(p=0.018)$ subscale scores compared with those of the fathers. 
Table 6

Mean differences in mothers' and fathers' perceived stress, anxiety and depression levels

\begin{tabular}{|llll|}
\hline & Mother N=229 & Father N=245 & Parents \\
\hline Mean (SD) & Mean (SD) & P (Cohen's d) \\
\hline Intrusive feeling (IES-6) & $3.98(0.97)$ & $4.28(0.82)$ & $<0.001(0.334)$ \\
\hline Hyperarousal (IES-6) & $3.80(1.03)$ & $3.90(0.98)$ & $0.28(0.099)$ \\
\hline Avoidance (IES-6) & $3.85(1.04)$ & $4.21(0.06)$ & $<0.001(0.488)$ \\
\hline Total Stress (IES-6) & $3.88(0.87)$ & $4.14(0.75)$ & $<0.001(0.320)$ \\
\hline Anxiety (HADS-A) & $3.31(0.48)$ & $3.43(0.42)$ & $0.002(0.266)$ \\
\hline Depression (HADS-D) & $3.64(0.40)$ & $3.71(0.32)$ & $0.018(0.193)$ \\
\hline Total HADS & $3.47(0.04)$ & $3.56(0.33)$ & $0.004(0.245)$ \\
\hline $\begin{array}{l}\text { Values are the mean (SD). HADS, Hospitality Anxiety and Depression Scale; IES-6, Impact of Event } \\
\text { Scale-6 }\end{array}$ & & \\
\hline
\end{tabular}

The analysis shows the importance of support from family and friends and the associations with perceived mental distress in mothers and fathers. The mothers reported significantly higher levels of mental distress compared with the fathers, except for the variable of "intrusiveness". There are no significant differences between support from family/friends and intrusiveness for parents. There is no significance between support from family/friends and hyperarousal for mothers.

\section{Discussion}

\section{Parent characteristics and perceived mental distress in the NICU}

The analysis shows that for the study sample, support from family and friends was the most significant important factor influencing parents' perceived anxiety and depression when their infant was admitted to the NICU. As expected, those parents who reported that their infant had good health also reported significantly less anxiety and depression symptoms compared with those parents reporting their infants' health as poor.

Family-centred care has been increasingly emphasized as an important and necessary element of neonatal intensive care (30). The Neonatal Satisfaction Survey (NSS-8) is based on FCC principles (36). This study examines whether satisfaction with health care in the NICU has an impact on parents' perceived anxiety and depression/mental health. We found that those parents who reported satisfaction with health care in NICUs reported a lower degree of depression symptoms than those parents who reported low satisfaction. 
It turns out that older parents experience less anxiety than younger parents. This is not a surprising finding. Other research has reported the same results (39-41). The parents with infants in a NICU are often in crisis situations, and we imagine that older people have experienced several crises and thus learned to deal with difficult situations. Younger people are still in a position where they are trying and failing and may thus be more anxious about the outcome.

We also found that parents with a high education level reported less anxiety than parents with a low education level. Other research (Liu et al., 2016) has also reported this outcome. It may be that their advanced level of knowledge makes these individuals safer. Such individuals are also often older. It may be that highly educated parents seek more information from doctors and nurses and thus achieve clearer and more precise information compared with parents with lower education levels. It may be that these individuals also understand the information they receive to a greater extent. This finding can remind clinics to be aware of informing younger parents without being asked for information to avoid gaps in important knowledge and to possibly reduce mental distress.

\section{Self-reported comparisons between the mental health of mothers and fathers and their support from family and friends when their infants are admitted to the NICU}

It can certainly be debated whether the three concepts of intrusive feelings, hyperarousal and avoidance are uncommon mental processes on the pathological scale. It is probably considered on the common scale to address an ongoing crisis in a critical situation. Nevertheless, some of the parents who face such a crisis may risk pathological disease. Thus, knowledge of the identification of pathological symptoms should be implemented in doctors and nurses in NICUs. We found different outcomes for parents but not large differences between them. Earlier studies have also reported that mothers experience more stress than fathers in critical situations $(3,12-14)$. The same results were found in our study. Parents may perceive themselves are being depressed without meeting the criteria of any diagnostic manual. Perceived depression should be considered serious, either as a diagnosable depression or as a situation that may develop into one. In this case, mental health assistance should be involved to determine what triggers depression regarding the current situation/other life events or a mood disorder. Therefore, this situation can clearly be more debated. We know that hyperarousal can be important for mothers when receiving support from friends and family but not for fathers. This is probably due to the same reason as those mentioned above. Mothers may have a different kind of security related to their feelings because they stay in the NICU all the time. In general, mothers often feel that they must have a sense of oversight regarding their family and may experience losing control in these situations.

Some interventions have been developed to reduce parental depression and anxiety in the NICU, such as educational content and therapy (42). These interventions have demonstrated that it is still unclear what is the best factor. Mothers and fathers experience support from family and friends in different ways. The reactions and mental health assistance in these situations can also be somewhat different, although the current analysis shows that such differences are not large. This study shows that mothers may be more dependent on support from close relationships than fathers. The support of family and friends is 
fundamental for both the mother's and father's mental distress, but it seems that this support is more important for the mothers' mental health than for that of fathers. The finding that mothers report higher levels of perceived depression and anxiety compared with fathers supports the findings of several previous studies. This outcome may be because fathers experience more mental input from the world around them because they also must take care of daily life outside the NICU. Mothers are mostly dependent on support from visitors to have a "mental time-out" consisting of input and news from the outside world. As a result, family and friends become more supportive individuals. Research (43) has noted that it is mainly unclear why mothers are more depressed, but it is thought that mothers are more active throughout the process. This thought can certainly be debated. Different continents and countries probably have different procedures regarding maternal and paternal involvement in the neonatal ward. In Norway, fathers and mothers should be equal in this process. Nevertheless, it appears that stress and anxiety can be reduced for both mothers and fathers through support from their friends and family.

The parents in this study who scored low on satisfaction with NICU care had an OR of being more depressive that was 3.36 times that of parents who reported being satisfied. Liu et al. (2016) pointed out that younger mothers and partners were more likely to experience new bouts of depression than were older mothers and partners. Enke and colleagues (2017) found the same result in their study. Fathers > 45 years old with low education levels are also in this category.

In the present study, parents answered the questionnaire just before their infant's discharge from the $\mathrm{NICU}$. We assume that at this time, parents are probably less distressed than they would have been either earlier in the process or immediately after discharge. The fear of dealing with problems alone at home may also be a contributing cause to increased mental distress after discharge. Just before discharge, parents probably experience a stabilized situation, i.e., they are often familiar with the health personnel, and they manage to care for the infant in a familiar and safe atmosphere closely monitored by NICU experts. The infant's health is acceptable or good, and the parents often look forward to taking their new family member home to the rest of their family.

\section{Limitations and strengths}

One limitation to this study is the response rate. However, the respondents represent $45 \%$ of the available study population, which is higher than average for Norwegian national patient-experience surveys (44). Several responses were not collected due to administrative errors. The absence of men/fathers during the period of their child's admission to the NICU is also a consideration. This survey is based on valid questionnaires and on both mothers and fathers ( $45 \%$ fathers). This is a strength because studies suggest that fathers' experiences with care in the NICU differ from those of mothers (45), which could therefore influence the fathers' evaluation of care. In our study, 568 parents answered the survey ( $45 \%$ of those available), which is a fair enough number of respondents from a wide geographical area in Norway. This population number also provides statistical power and protection from bias. However, we cannot predict how the non-responding group would have answered the survey. One limitation is that only half of the units treated infants with a GA of $<23$ weeks, which could influence some of the results. In addition, 
we do not know what mental health the parents had before their infant's admission to the NICU; both parents could have suffered from mental distress prior to the time of admission.

\section{Conclusion}

The support of family and friends is the most fundamental aspect of help for both mothers and fathers when they have a child admitted to the NICU, but this factor seems more important for mothers' mental health than for fathers'. Parents who perceive themselves to have a low degree of depression are more satisfied with NICU care than those who perceive themselves to have higher levels of depression. The current study shows that older parents experience less distress/stress than younger parents when they are in the NICU situation. Highly educated parents show less stress and anxiety than those with less or no education. Their level of knowledge seems to make them feel safer than other parents.

\section{Abbreviations}

NICU- Neonatal Intensive Care Unit

FCC- Family-Centred Care

HADS -Hospital Anxiety and Depression Scale

IES-6- Impact of Events Scale-Revised

ASD - Acute stress disorder

PTSD - Post-traumatic stress disorder

PPD - Postpartum depression

\section{Declarations}

\section{Ethics approval and consent to participate}

The study was conducted according to the Helsinki declaration. This project was approved by the Regional Committees for Medical and Health Research Ethics2015/386/REK nord, 24.September 2015. The project is approved from the Norwegian Data Protection Officials.

Signed informed consent was obtained from each participant before they participated in the study. Participants were informed of their rights to withdraw from the study at any time. The anonymity of participants was maintained, and assurance was given that all information would be treated in absolute confidence. Participants were also provided with a written information sheet on the study and their rights regarding participation and the option of withdrawing at any time.

\section{Consent for publication:}


Not applicable

\section{Availability of data and materials:}

The data used in the current study are available from the corresponding author on reasonable request.

\section{Competing interests:}

All authors declare that they have no competing interests.

\section{Funding:}

The study received no funding.

\section{Authors contributions:}

$\mathrm{IHH}$, design, data collection, transcription, analysis, interpretation of data, manuscript preparation; MSF, manuscript preparation, drafting the manuscript and revising it critically for important intellectual content. All authors have read and approved the study.

FPV, drafting the manuscript and revising it critically for important intellectual content, writing assistance, and analysis.

The first author has full access to all the data in the study as well as having monitored and taken part in the collecting of data. The data has been shared with an objective part. The first author takes responsibility for the integrity and accuracy of the data analysis.

\section{Acknowledgements}

The authors are grateful to the contact persons in all the six NICUs (Troms $\varnothing$, Bodø, Levanger, St. Olav, Ålesund and Lillehammer) for generously giving their time to collecting participants for the study. We also thank the parents for participating in the study.

\section{References}

1. Carter JD, Mulder RT, Bartram AF, Darlow BA. Infants in a neonatal intensive care unit: parental response. Archives of disease in childhood Fetal and neonatal edition. 2005;90(2):F109-13.

2. Bener A. Psychological distress among postpartum mothers of preterm infants and associated factors: a neglected public health problem. Revista brasileira de psiquiatria (Sao Paulo, Brazil : 1999). 2013;35(3):231-6.

3. Agrawal R, Gaur A. Parent stress in neonatal intensive care unit: an unattended aspect in medical care. International Journal of Contemporary Pediatrics. 2016;4(1):148-53.

4. Ionio C, Colombo C, Brazzoduro V, Mascheroni E, Confalonieri E, Castoldi F, et al. Mothers and Fathers in NICU: The Impact of Preterm Birth on Parental Distress. Europe's Journal of Psychology. 
2016;12(4):604-21.

5. Busse M, Stromgren $K$, Thorngate $L$, Thomas KA. Parents' responses to stress in the neonatal intensive care unit. Crit Care Nurse. 2013;33(4):52-9; quiz 60.

6. Prouhet PM, Gregory MR, Russell CL, Yaeger LH. Fathers' Stress in the Neonatal Intensive Care Unit: A Systematic Review. Advances in neonatal care : official journal of the National Association of Neonatal Nurses. 2018;18(2):105-20.

7. Schappin R, Wijnroks L, Venema MMU, Jongmans MJ. Rethinking stress in parents of preterm infants: a meta-analysis. PloS one. 2013;8(2):e54992.

8. Franck LS, Cox S, Allen A, Winter I. Measuring neonatal intensive care unit-related parental stress. J Adv Nurs. 2005;49(6):608-15.

9. Chow A, Mayer EK, Darzi AW, Athanasiou T. Patient-reported outcome measures: the importance of patient satisfaction in surgery. Surgery. 2009;146(3):435-43.

10. Lefkowitz DS, Baxt C, Evans JR. Prevalence and correlates of posttraumatic stress and postpartum depression in parents of infants in the Neonatal Intensive Care Unit (NICU). J Clin Psychol Med Settings. 2010;17(3):230-7.

11. Flacking R, Lehtonen L, Thomson G, Axelin A, Ahlqvist S, Moran VH, et al. Closeness and separation in neonatal intensive care. Acta Paediatrica. 2012;101(10):1032-7.

12. Carter JD, Mulder RT, Darlow BAJP, health $m$. Parental stress in the NICU: The influence of personality, psychological, pregnancy and family factors. 2007;1(1):40-50.

13. Jackson K, Ternestedt BM, Schollin J. From alienation to familiarity: experiences of mothers and fathers of preterm infants. J Adv Nurs. 2003;43(2):120-9.

14. Van der Pal S, Maguire C, Le Cessie S, Wit J, Walther F, Bruil JJAP. Parental experiences during the first period at the neonatal unit after two developmental care interventions. 2007;96(11):1611-6.

15. Baia I, Amorim M, Silva S, Kelly-Irving M, de Freitas C, Alves E. Parenting very preterm infants and stress in Neonatal Intensive Care Units. Early Hum Dev. 2016;101:3-9.

16. Beck CT. Postpartum depression: it isn't just the blues. The American journal of nursing. 2006;106(5):40-50; quiz -1.

17. Ballantyne M, Benzies KM, Trute B. Depressive symptoms among immigrant and Canadian born mothers of preterm infants at neonatal intensive care discharge: a cross sectional study. BMC Pregnancy Childbirth. 2013;13 Suppl 1(Suppl 1):S11.

18. Gonulal D, Yalaz M, Altun-Koroglu O, Koltursay N. Both parents of neonatal intensive care unit patients are at risk of depression. Turkish J Pediatr. 2014;56(2):171-6.

19. Lefkowitz DS, Baxt C, Evans JR. Prevalence and correlates of posttraumatic stress and postpartum depression in parents of infants in the Neonatal Intensive Care Unit (NICU). Journal of clinical psychology in medical settings. 2010;17(3):230-7.

20. McCabe K, Blucker R, Gillaspy JA, Jr., Cherry A, Mignogna M, Roddenberry A, et al. Reliability of the postpartum depression screening scale in the neonatal intensive care unit. Nurs Res. 2012;61(6):441- 
5.

21. Yaman S, Altay N. Posttraumatic stress and experiences of parents with a newborn in the neonatal intensive care unit. Journal of Reproductive and Infant Psychology. 2014:1-13.

22. Aftyka A, Rybojad B, Rozalska-Walaszek I, Rzonca P, Humeniuk E. Post-traumatic stress disorder in parents of children hospitalized in the neonatal intensive care unit (NICU): medical and demographic risk factors. Psychiatria Danubina. 2014;26(4):347-52.

23. Turner $M$, Chur-Hansen A, Winefield $H$, Stanners $M$. The assessment of parental stress and support in the neonatal intensive care unit using the Parent Stress Scale - Neonatal Intensive Care Unit. Women and birth : journal of the Australian College of Midwives. 2015;28(3):252-8.

24. Alkozei A, McMahon E, Lahav A. Stress levels and depressive symptoms in NICU mothers in the early postpartum period. The journal of maternal-fetal \& neonatal medicine : the official journal of the European Association of Perinatal Medicine, the Federation of Asia and Oceania Perinatal Societies, the International Society of Perinatal Obstet. 2014;27(17):1738-43.

25. Mendelson T, Cluxton-Keller F, Vullo GC, Tandon SD, Noazin S. NICU-based Interventions To Reduce Maternal Depressive and Anxiety Symptoms: A Meta-analysis. Pediatrics. 2017;139(3).

26. Cheng ER, Kotelchuck M, Gerstein ED, Taveras EM, Poehlmann-Tynan J. Postnatal Depressive Symptoms Among Mothers and Fathers of Infants Born Preterm: Prevalence and Impacts on Children's Early Cognitive Function. J Dev Behav Pediatr. 2016;37(1):33-42.

27. Halpern LF, Brand KL, Malone AF. Parenting stress in mothers of very-low-birth-weight (VLBW) and full-term infants: a function of infant behavioral characteristics and child-rearing attitudes. J Pediatr Psychol. 2001;26(2):93-104.

28. Olafsen KS, Ronning JA, DahI LB, Ulvund SE, Handegard BH, Kaaresen PI. Infant responsiveness and maternal confidence in the neonatal period. Scandinavian journal of psychology. 2007;48(6):499509.

29. Cooper LG, Gooding JS, Gallagher J, Sternesky L, Ledsky R, Berns SD. Impact of a family-centered care initiative on NICU care, staff and families. J Perinatol. 2007;27 Suppl 2:S32-7.

30. Gooding JS, Cooper LG, Blaine AI, Franck LS, Howse JL, Berns SD. Family support and familycentered care in the neonatal intensive care unit: origins, advances, impact. Seminars in perinatology. 2011;35(1):20-8.

31. Mohammad A, Hossein N, Masoumeh B, Mohammad Asghari J, Kobra R. Effect of Family-centered Intervention in Neonatal Intensive Care Unit on Anxiety of Parents. International Journal of Pediatrics. 2017;5(6):5101-11.

32. Bastani F, Abadi TA, Haghani H. Effect of Family-centered Care on Improving Parental Satisfaction and Reducing Readmission among Premature Infants: A Randomized Controlled Trial. Journal of clinical and diagnostic research : JCDR. 2015;9(1):Sc04-8.

33. Banerjee J, Aloysius A, Platonos K, Deierl A. Family centred care and family delivered care-What are we talking about? Journal of Neonatal Nursing. 2018;24(1):8-12. 
34. Hagen IH, Iversen VC, Nesset E, Orner R, Svindseth MFJBHSR. Parental satisfaction with neonatal intensive care units: a quantitative cross-sectional study. 2019;19(1):37.

35. Polit DF, Beck CT. Nursing Research : generating and assessing evidence for nursing practice. 10th ed. ed. Philadelphia: Wolters Kluwer; 2017.

36. Hagen IH, Svindseth MF, Nesset E, Orner R, Iversen VC. Validation of the Neonatal Satisfaction Survey (NSS-8) in six Norwegian neonatal intensive care units: a quantitative cross-sectional study. BMC health services research. 2018;18(1):222.

37. Bjelland I, Dahl AA, Haug TT, Neckelmann D. The validity of the Hospital Anxiety and Depression Scale. An updated literature review. J Psychosom Res. 2002;52(2):69-77.

38. Zigmond AS, Snaith RP. The hospital anxiety and depression scale. Acta Psychiat Scand. 1983;67(6):361-70.

39. Liu C, Cnattingius S, Bergstrom M, Ostberg V, Hjern A. Prenatal parental depression and preterm birth: a national cohort study. BJOG. 2016:n/a-n/a.

40. Enke C, Oliva Y Hausmann A, Miedaner F, Roth B, Woopen C. Communicating with parents in neonatal intensive care units: The impact on parental stress. Patient Education and Counseling. 2017;100(4):710-9.

41. Enke C, Oliva YHA, Miedaner F, Roth B, Woopen C. Communicating with parents in neonatal intensive care units: The impact on parental stress. Patient Educ Couns. 2017;100(4):710-9.

42. Mendelson T, Cluxton-Keller F, Vullo GC, Tandon SD, Noazin S, Mendelson T. NICU-based Interventions To Reduce Maternal Depressive and Anxiety Symptoms: A Meta-analysis. Pediatrics. 2017;139(3).

43. Narayanan MK, Nærde A. Associations between maternal and paternal depressive symptoms and early child behavior problems: Testing a mutually adjusted prospective longitudinal model. Journal of Affective Disorders. 2016;196:181-9.

44. Bjertnaes OA, Sjetne IS, Iversen HH. Overall patient satisfaction with hospitals: effects of patientreported experiences and fulfilment of expectations. BMJ Quality \& Safety. 2012;21(1):39.

45. Candelori C, Trumello C, Babore A, Keren M, Romanelli R. The experience of premature birth for fathers: the application of the Clinical Interview for Parents of High-Risk Infants (CLIP) to an Italian sample. Front Psychol. 2015;6:1444.

\section{Supplementary Files}

This is a list of supplementary files associated with this preprint. Click to download.

- STROBEchecklistcrosssectionalappendix1.docx 